Investigaciones Fenomenológicas, n. 10, 2013, 105-119.

e-ISSN: $1885-1088$

\title{
HaCia una fenomenología enCARnADA. Sobre la filosofía del CUERPo de NATALIE Depraz
}

\author{
Towards an Embodied Phenomenology. \\ On Body Philosophy of Natalie Depraz
}

\begin{abstract}
Resumen: Este artículo pretende servir de breve introducción a la filosofía de Natalie Depraz, principalmente a respecto de la cuestión del cuerpo, tema que la autora desarrolla en el libro Lucidité du corps. Para ello nos servimos de dos claves de lectura entrelazadas entre sí, que son la fenomenología experiencial y la fenomenología de la atención, desarrolladas en los últimos trabajos de Natalie Depraz. A partir de estas claves, y atravesando los temas centrales del trabajo sobre la lucidez del cuerpo, se intentará recuperar otros dos temas principales de su pensamiento, a saber, la alterología y el empirismo trascendental, para dar una visión de conjunto de su filosofía, elaborada como una fenomenología práctica en constante diálogo con las ciencias cognitivas y las tradiciones espirituales.
\end{abstract}

Palabras clave: Cuerpo, atención, alteridad, intersubjetividad, lucidez.

\author{
Roberto Menéndez \\ Universidad de Granada, España / \\ Université de Rouen, Francia \\ Roberto_obarri@yahoo.es
}

\begin{abstract}
This essay intends to be a brief introduction to Natalie Depraz's philosophy, and it is closely related to the issue of the body, which is a subject developed by the author in her book Lucidité du corps. In order to achieve this goal we make use of two interwoven reading keys, both the experiential phenomenology and the attention phenomenology which are explained in Natalie Depraz's latest works. From these keys and crossing the central points of the work on the lucidity of the body, we will attempt to retrieve another two main issues of her thought, i.e. alterology and transcendental empirism. We aim at giving a global vision of her philosophy, which has been developed as a practical phenomenology in continuous dialogue with cognitive sciences and spiritual traditions.
\end{abstract}

Key Words: Body, Attention, Alterity, Intersubjectivity, Lucidity.

\section{ENCUADRE DE UNA FENOMENOLOGÍA EXPERIENCIAL}

Una de las mejores formas de aproximarse al trabajo de la filósofa francesa Natalie Depraz tiene como puntos de partida su voluntad y vocación de reelaborar la fenomenología como una práctica experiencial. Para ello, la metodo- 
logía de la reducción fenomenológica se verá animada por algunos criterios que vamos a enumerar brevemente. En primer lugar, hay que poner en suspenso todo prejuicio sobre la imposibilidad de practicar la fenomenología. En segundo lugar, hay que entender la épochè como una praxis, lo que equivale a incorporar la reducción mediante gestos concretos y según ejemplos que tengan como punto de partida y como punto de llegada la experiencia misma. Esta praxis reductiva comienza con la lectura misma de los textos - según la expresión utilizada por Depraz de "leer como fenomenólogo"-, pasa por una práctica de la presencia a sí, y converge, en algunos casos, en una práctica de la escritura igualmente entendida bajo el lema "escribir como fenomenólogo". Este recorrido, como veremos, no se funda en la reflexión -o actividad reflexiva-, sino en la atención -o dinámica atencional-, aquella que se expresa en gestos y en movimientos que no pueden ser entendidos sino es a través del cuerpo.

De este modo, y orientándonos por la etimología, es preciso leer los textos de Natalie Depraz como tejidos vivos, que incluyen la gestualidad propia de la escritura y de la lectura, y que constituyen una textura que implica e impregna el discurso según la modalidad de las relaciones intersubjetivas. Para ello, $\mathrm{N}$. Depraz tiene mucho cuidado a la hora de llevar nuestra atención a las dimensiones y dinámicas de la vida en las que opera una conciencia sutil: no se desea una reflexión intelectual y distanciada sobre la propia vida, sino una sensibilidad fina que permita apreciar los relieves de una conciencia de sí encarnada en un cuerpo que es, sobre todo, ligereza y lucidez. De igual modo, Natalie Depraz es muy cuidadosa a la hora de hacer comparecer la sabiduría práctica del cuerpo que somos, así como el conocimiento primordial que descubre una alteridad a sí anterior a todo trabajo de la reflexión, revelándonos con ello la corporalidad a través de una reflexividad práctica que compromete la vida entera en una envoltura de presentimientos carnales. Una vida atenta, o atentiva, más que una vida reflexiva, y una fenomenología práctica, experiencial, más que una fenomenología meramente exegética.

\section{MOTIVOS DE UNA FENOMENOLOGÍA DE LA ATENCIÓN}

Practicar la reducción, entonces, a propósito de una fenomenología experiencial en primera persona. No para ir en busca de la alteridad, sino para 
aprender a darle acogida. Esta voluntad implica una revaloración de los elementos que conforman la metodología de la reducción fenomenológica. Para evitar una fractura excesiva entre la actividad reflexiva y la así llamada vida prerreflexiva, N. Depraz propone una lectura alternativa de las Ideas relativas... de Husserl, para destacar el papel de la atención en contraste con el de la reflexión. Con este objetivo, Natalie Depraz trata de orientar nuestra mirada hacia la dinámica atencional de la corriente de conciencia, modalidad de la vida intencional que atraviesa todas sus capas, y que viene a coser las roturas que dejaban tras de sí, en primer lugar, las diferencias entre la reflexión y la percepción, y en segundo lugar, entre la vida reflexiva y la vida prerreflexiva. De esto modo se destacará el papel fundamental de la atención como aquel modulador que sirve de fundamento al giro de mirada en qué consiste la reflexión, permitiendo el paso de un modo de "mirar" a otro.

Natalie Depraz elabora una suerte de inversión de los papeles de la intencionalidad y la atencionalidad, reeducando con ello el concepto común de atención, que suele referir a momentos puntuales, aquellos en los que estamos en estado de alerta, vigilantes ante un suceso inminente. Contra esta acepción, N. Depraz propone un concepto de atención referida a una propiedad moduladora inmanente, que no se reduce a un subgénero de la percepción, ni tampoco a una modalidad de la reflexión. La atención propuesta excede desde dentro a la vida perceptiva, e impregna otras capas de la vida intencional, como la memoria, la fantasía, etc ${ }^{1}$. De este modo podemos decir que la atención no está volcada solamente sobre los objetos trascendentes, como en el caso de la percepción exterior, ni tampoco está vuelta sobre la vida inmanente como en el caso de la reflexión. Antes bien, la atención entreteje ambas dimensiones haciendo posible un cambio en la dirección de la "mirada" que no tenga como resultado una modificación sustancial de la vivencia, como en el caso de la reflexión, sino una mayor apertura a la misma, así como a la conciencia que la acompaña. La atención, entonces, no es un acto concreto entre otros -el estado de alertasino un modulador de la vida intencional que permite precisamente el paso su-

\footnotetext{
1 "L'activité attentionnelle nourrit, telle une praxis quotidienne, chacun des actes intentionnels de ma conscience, perceptif, remémorant, imaginatif, empatique" (Depraz, Natalie, "Attentionnalité et intentionnalité : L'attention comme «modulation» (Où est la phénoménologie de l'attention que Husserl avait le projet de mettre en oeuvre ?)", en Jocelyn Benoist (ed.), Husserl, Paris, Éditions du Cerf, 2008, p. 235) ["La actividad intencional nutre, como una praxis cotidiana, cada uno de los actos de mi conciencia: perceptivo, rememorante, imaginativo, empático"]
} 
cesivo de unas actividades y otras, en las cuales vienen a enfocarse unos u otros aspectos del fenómeno sin que ello conlleve una modificación esencial de la vivencia.

De conformidad con lo dicho, el mismo estilo de N. Depraz se caracteriza por su cuidada forma de llevar la atención - sin llamar la atención- hacia la conciencia latente que atraviesa todas nuestras actividades, comenzando por revelar la dinámica atencional implícita en la lectura misma de sus textos. Más que un acto inaugurado por la autosuficiencia del sujeto, la atención está en íntima relación con la afección, o, en otras palabras, con la atracción que el componente hylético de las diferentes vivencias ejerce sobre la conciencia. Desde esta perspectiva, la vida de conciencia es atencional de parte a parte, y la actividad de la atención, como tal, inagotable. Por este motivo N. Depraz prefiere utilizar el concepto de "dinámica atencional", que vendría a sustituir, desde otro punto de vista, al de "vida pre-reflexiva", utilizado generalmente para hacer un contraste con la vida reflexiva. Con ello, antes de elevar la falla que va de lo reflexivo a la pre-reflexivo, se estaría abriendo un pasadizo entre ambas dimensiones a partir de dinámicas de ida y vuelta².

Tales dinámicas tendrían por efecto un devenir-consciente, resultado de una reducción fenomenológica entendida como práctica de la presencia a sí. La atención no sería en este contexto un ingrediente constitutivo de la conciencia, en un sentido estático. Antes bien, las dinámicas atencionales serían constituyentes de la conciencia. Dicho en otras palabras, el devenir-consciente sería el fruto de las dinámicas atencionales, en un sentido genético. Así, la atención sería una suerte de a priori del devenir-consciente, pero no como condición formal de posibilidad. Natalie Depraz no se sirve de las imágenes y los ejemplos gestuales de un modo metafórico. Entiende que la atención es primitivamente corporal, y que se expresa en el movimiento de los ojos, en la expresión del rostro, etc. La atención es una constante de la vida inmanente, y entrelaza

\footnotetext{
2 "Tandis que I'intentionnalité est un modèle formel de la strucuture de la conscience, dont l'ouverture réside dans une orientation linéaire vers l'objet, l'attentionnalité en tant que modulation fournit à chaque acte de notre conscience une densité de fluctuations matérielles qui est due à ses variations internes et à sa changeabilité concrète" (Depraz, Natalie, Attentionnalité et intentionnalité, op. cit., p. 240) ["Mientras que la intencionalidad es un modelo formal de la estructura de la conciencia, en la cual la apertura reside en una orientación linear hacia el objeto, la atencionalidad en tanto que modulación proporciona a cada acto de nuestra conciencia una densidad de fluctuaciones materiales debido a sus variaciones internas y a su cambiabilidad concreta"].
} 
toda actividad intencional en el seno de una y la misma corriente de vivencias ${ }^{3}$. Los gestos definen tanto el funcionamiento general de la atención como la actividad práctica de la reducción ${ }^{4}$. Natalie Depraz llega a ejemplificar la estructura trascendental con un esqueleto que solo se conforma como cuerpo vivo gracias a la dinámica atencional. Así, el cuerpo, como cuerpo "de carne y hueso", vendría alimentado tanto por la dinámica atencional como por su estructura trascendental, lo que conduce, como veremos, a la hipótesis del "empirismo trascendental" ${ }^{5}$. Es por ello que una fenomenología de la atención no puede conducirnos sino a la cuestión corporal. En este sentido, la atención será entendida como una actividad encarnada que atraviesa todos los planos de la intencionalidad, y que además tiene el valor añadido de confrontar al sujeto consigo mismo de un modo inmediato:

\begin{abstract}
C'est le fonctionnement en acte de notre esprit conscient, de nos états perceptifs, de nos qualités émotionnelles, la gestion de nos vécus temporels qui se trouve avec l'attention revisité c'est-à-dire aussi réenraciné dans notre corps. Au fond, l'enjeu de la mise au premier plan de l'attention est crucial dans le cadre d'une désidéalisation de la phénoménologie, c'est-à-dire de son effectuation, bref, de sa réalisation pragmatique. ${ }^{6}$
\end{abstract}

\footnotetext{
3 "Il s'agit d'une sorte d'activité transversale de ma conscience qui est orthogonale à la linéarité horizontale de I'orientation intentionnelle, puisqu'elle nous donne accès, telle une onde de variations et de vibrations, à la profondeur mobile de notre conscience. Aussi l'attention ne semble-t-elle pas être liée à un acte intentionnel spécifique, qu'il soit perceptif, remémorant ou imaginatif : elle est associée à tous à titre de modulateur, à chacun d'entre eux, tout à la fois 'inessentiel' et 'inévitable'" (Depraz, Natalie Attentionnalité et intentionnalité, op. cit., p. 241) ["Se trata de una suerte de actividad transversal de mi conciencia que es ortogonal a la linealidad horizontal de la orientación intencional, en tanto que nos da acceso, como una onda de variaciones y de vibraciones, a la profundidad móvil de nuestra conciencia. De este modo la atención no parece estar ligada a un acto intencional específico, sea perceptivo, rememorante o imaginativo: está asociada a todos y a cada uno de ellos a título de modulador, de modo 'inesencial' y a la vez 'inevitable'"']

4 "L'attention a besoin d'être réenracinée dans ses postures corporelles (kinesthésiques, visuelles et affectives), qui nomment sa qualité oeganique de vécu, mais aussi dans sa portée signitive concrète" (Depraz, Natalie, Plus sur Husserl. Une phénoménologie experièncielle, Neuilly, Atlante, 2009, p. 50) ["La atención necesita ser reenraizada en las posturas corporales (kinestésicas, visuales y afectivas) que nombran su cualidad de vivencia, pero también su alcance signitivo concreto"]

5 "Il ne s'agit pas par là de nier la pertienence de l'intentionnalité, mais de relativiser se primauté en tant que modèle global et propriété centrale voire exclusive de la conscience, et ce, du fait de sa présentation en tant qu'architecture formelle, structurelle et générale. Bref, on pourrait à partir de là proposer la distinction entre une visée attentionnelle d'orientation vécue (qui peut être soit organique, soit indicatrice), et une visée intentionnelle d'appréhension objectivante (percpetive et gnoséologique)" (Depraz, Natalie, Plus sur Husserl, op. cit., p. 51) ["No se trata con ello de negar la pertinencia de la intencionalidad, sino de relativizar su primacía en tanto que modelo global y propiedad central e incluso exclusiva de la conciencia, partiendo del hecho de su presentación como arquitectura formal, estructural y general. En pocas palabras, se podría a partir de aquí proponer la distinción entre una mención atencional de orientación vivida (que puede ser bien orgánica, bien indicativa), y una mención intencional de aprehensión objetivamente (perceptiva y gnoseológica)"]

${ }^{6}$ Depraz, Natalie, Comprendre la phénoménologie. Une pratique concrète, Paris, Armand Colin, 2006, p. 89. ["Es el funcionamiento en acto de nuestro espíritu consciente, de nuestros estados perceptivos y de
} 
Así pues, la reducción que Natalie Depraz propone es eminentemente práctica, basada en la gestualidad y en la cualidad atencional que impregna toda la vida de conciencia. En resumen, si la reflexión es un tipo concreto de giro de la mirada, la dinámica atencional envuelve todos los gestos y las orientaciones de la mirada con las que las diferentes formas de intencionalidad se desplazan por el horizonte espacio-temporal a una sus relieves emocionales e imaginarios. Una fenomenología "atencional" desborda el campo de una fenomenología reflexiva, implicando de un modo definitivo la cuestión insoslayable de la corporalidad.

L'importance de l'attention par rapport à la reflexion, laquelle a toujours été privilégiée par les philosophies de la subjectivité (de Descartes à Husserl via Fichte), est de nous obliger à nous confronter à notre expérience immédiate, à son intensité, à ses failles, à sa plasticité et à sa rythmique. On peut mesurer son rythme attentionnel, sa qualité d'attention, prendre conscience de ses lacunes et de ses performances : c'est la tout l'enjeu d'une phénoménologie pratique. En revanche, la réflexion nous oriente d'emblée vers le champ des hypothèses, des idées, bref, de la spéculation, car on y est invité à idéaliser notre expérience de sujet : il y a immanquablement risque de dé-réalisation, c'est-à-dire aussi d'abstraction. D'où le lien entre l'activité réflexive et la connaissance par images, où prennent sens les notions de reflet, de miroir, de figure, mais aussi de dédoublement, de duplicité et de représentation etc. Bref, alors que la réflexivité ressortit à l'idéalité irréalisante de l'expérience, l'attention nous reconduit à l'inscription concrère et incarnée de cette même expérience dans l'examen minutieux de notre relation interne à nousmêmes. $^{7}$

\footnotetext{
nuestras cualidades emocionales, a una con la gestión de nuestras vivencias temporales, los que se encuentran revisitados a través de la atención, es decir, también, reenraizados en nuestro cuerpo. En el fondo, lo que pone en juego al traer a primer plano la atención resulta crucial en el marco de una desidealización de la fenomenología, es decir, de su efectuación, o lo que es lo mismo, de su realización pragmática"]

7 Depraz, Natalie, Comprendre la phénoménologie, op. cit., p. 88-89. ["La importancia de la atención en relación a la reflexión, la cual ha sido siempre privilegiada por los filósofos de la subjetividad (de Descartes a Husserl vía Fichte), es la de obligar a confrontarnos con nuestra experiencia inmediata, con su intensidad, sus fallas y fisuras, con su plasticidad y su rítmica. Se puede medir el ritmo atencional, su cualidad de atención, tomar conciencia de sus deficiencias y de sus rendimientos: aquí descansa toda la apuesta de una fenomenología práctica. Por el contrario, la reflexión nos orienta de entrada hacia el campo de las hipótesis, de las ideas, en pocas palabras, de la especulación, en la medida en que somos invitados a idealizar nuestra experiencia de sujetos: hay irremediablemente un riesgo de des-realización, esto es, de abstracción. De aquí se sigue el enlace entre la actividad reflexiva y el conocimiento por imágenes, de donde obtienen el sentido nociones como reflejo, espejo, figura, pero también desdoblamiento, duplicidad, representación, etc. En conclusión, mientras que la reflexividad resalta la idealidad irrealizante de la experiencia, la atención nos reconduce a la inscripción concreta y encarnada de esta misma experiencia en el examen minucioso de nuestra relación interna con nosotros mismos"].
} 


\section{ENTRE LA OPACIDAD Y LA TRANSPARENCIA, LA LUCIDEZ DEL CUERPO}

Uno de los lugares donde comprobamos esta apuesta al concepto de atención, así como a la reducción entendida como praxis, es en Lucidité du corps, donde Natalie Depraz desarrolla un discurso en el que somos conducidos a nuestra dimensión corporal, a través de un trabajo analítico entreverado de ejemplos prácticos accesibles a la experiencia del lector. El objetivo, dejar que sea nuestro propio cuerpo, en silencio, o susurrando, el que lleve nuestra atención hacia su sabiduría y sensibilidad, las cuales nos pasan desapercibidas la mayor parte del tiempo. Ya lo hemos dicho: en vez de considerar la reflexión como una suerte de autopsia hecha a un cuerpo muerto; antes de entenderla como una operación hecha a un cuerpo anestesiado, la filosofía de Natalie Depraz conduce nuestra atención hacia la hiperestesia del cuerpo, destacando su ligereza y su movilidad así como sus límites, aquellos que pueden ser superados mediante el esfuerzo y el ejercicio.

La filosofía de Natalie Depraz despliega una estrategia paciente que consiste en acceder a la conciencia que el cuerpo complica, aquella que normalmente permanece olvidada. La causa es que el cuerpo, en su cercanía - tan cercano que "el cuerpo es lo que somos" - no alcanza a destacarse en toda su lucidez, y la mayor parte de las veces o bien se mantiene en segundo plano o bien se objetiva en la vida cotidiana, como un instrumento más que no llama nuestra atención. Para volver sobre la condición preciosa del cuerpo, N. Depraz moviliza algunos ejemplos que van a despertar poco a poco la conciencia dormida de nuestra condición carnal: la danza, el erotismo o el embarazo, experiencias a las que N. Depraz nos invita a dar acogida.

No se trata de redundar en la apercepción corporal, sino de impregnarla en un saber-hacer fruto del ejercicio y del hábito. La posible atención a este saberhacer como tal nos pone tras la pista de la reducción trascendental, donde pasamos de lo vivido a la vivencia, operando así una alteración del saber aperceptivo del cuerpo. Pasamos del cuerpo vivido (corps vécu) a la "carne" corporal (chair corporelle), desubstancializando el cuerpo como cuerpo físico orgánico. La emoción juega un papel fundamental, pues le corresponde un tipo de movimiento no objetivable, es decir, un movimiento sin medida; movimiento del 
cuerpo como "chair", como cuerpo vivo ${ }^{8}$. La emoción desborda los límites de la piel hacia dentro y hacia fuera, anulando el dualismo entre sujeto y objeto y dando acogida a lo otro dentro de sí. En efecto, cuando decimos que algo o alguien nos emociona, utilizamos la forma pronominal, que alude a una afección hacía sí, afección que en este caso consiste en un movimiento, e-moción. Natalie Depraz trata con ello de desobjetivar el cuerpo, y para ello aborda también el papel de los sentidos en la superación de la imagen estática de un cuerpo limitado por la piel y entendido como cuerpo físico de cara a las cosas.

Los sentidos, así como su envoltura sentimental, nos funden en el mundo, y las más de las veces hacen que el sujeto se olvide de sí en la atención a las cosas. Queda un sujeto latente en un cuerpo vivo cuyos sentidos y sentimientos lo llevan a estar en el mundo, impregnando alteridad. Natalie Depraz toma partido por los sentidos menos estudiados en filosofía, como son el gusto y el olfato, precisamente aquellos cuya difusividad puede revertir en un reconocimiento de la esfera sensorial en general, normalmente reducida a la diferencia fuerte que marca la percepción visual entre sujeto y objeto. El texto avanza con una descripción de diferentes capas que recubren las anteriores, implicando la plasticidad del cuerpo vivido con la difusividad de los sentidos, a su vez envueltos por el sentimiento enunciado en la metáfora del corazón. La desobjetivación pasa por vencer los puntos de localización, y entender tales dimensiones según la circularidad que expresa el flujo sanguíneo, el movimiento de la emoción y la plasticidad del cuerpo vivido. Natalie Depraz refiere el concepto de sinestesia, no como diagnóstico clínico, sino para destacar un régimen de vivencias que son fruto de la reducción a la "chair".

Seule une conception intégrée, holistique des différents sens à la lumière de leur syensthésie immanente permet de rompre avec l'idée naïve d'une fonctionnalité autonome de chaque sens. On entend ansi le caractère transcendantal de la diffusivié d'un sens ou d'une sensation à l'ensemble du sentir : la transcendantalité du sentir est à la mesure de la globalité de sa diffusivité charnelle. ${ }^{9}$

\footnotetext{
${ }^{8}$ En español traducir "chair" por "carne" puede ser engañoso. Aunque tal es la traducción correcta, hay que hacer notar que en español el concepto de carne nos envía con facilidad a la carne como alimento, es decir, a la carne muerta, objetivada. Los franceses, en cambio, tienen un concepto propio para referir a la carne como alimento - viande-, significando el concepto de "chair" en todos los casos "carne" como cuerpo vivo, el propio. Es por esta imposibilidad de traducir directamente "chair" por "carne", que dejaré el concepto francés entre comillas, entendiendo con ello la referencia al cuerpo como "cuerpo vivo".

${ }^{9}$ Depraz, Natalie, Lucidité du corps. De l'empirisme transcendental en phénoménologie. Dordrecht, Kluwer Academic Publishers, 2001, p. 29 ["Solo una concepción integrada y holística de los diferentes sen-
} 
La atención está llevada hacia los límites que posibilitan una inter-acción y una inter-pasión entre diferentes órdenes de la corporalidad. La circularidad no es cerrada, sino abierta, en un juego constante de movimientos centrífugos y centrípetos. Con ello el corazón gana fluidez, y, al referir a la sangre que mueve, deja de estar localizado. Es la metáfora de la emoción. Los sentimientos, de igual modo, ganan cuerpo, se encarnan en gestos y expresiones. No se trata solo de la alteración interna, sino de la acogida de la alteridad. N. Depraz habla a propósito de la posibilidad de un cultivo de la circularidad; cultivo de las diferentes dimensiones que aquí revisamos. Cultivo, en suma, propiciado por el ejercicio y la práctica, con la finalidad de ganar una mayor apertura hacia las vibraciones y resonancias de los demás; una mayor sensibilidad, tanto ética como erótica.

La résonnance et la promesse d'une disponibilité ouverte à autrui $[. .$.$] La réson-$ nance met en relief, 1) via l'intersubjectivité communautaire, l'expérience de la chair spiritualle diffusive, et 2) via l'inter-affection passive, l'expérience du flux charnel émotionel. Avoir une résonnance, trouver un écho, autant d'expresions qui témoignent dans notre langue de cet accord inter-affectif, qui est fait de compréhension, d'affinité et de sympathie. ${ }^{10}$

En el segundo capítulo del libro nos encontraremos con una revalorización de la temporalidad, encarnada y vuelta sobre el futuro. La idea rectora es ahora la de la autoantecedencia: protención de un cuerpo volcado hacia una alteridad que es sobre todo temporal, dimensión futuriza de la acogida. "Notre corps, le corps que nous sentons et que nous éprouvenos, ce corps qui est notre Urpraxis, recèle de façon primordiale ce pouvoir de s'anticiper lui-même à trite de corporéité s'inscrivant dans la spatio-temporalité" (Depraz, N., Lucidité du

tidos a la luz de su sinestesia inmanente permite romper con la idea ingenua de una funcionalidad autónoma de cada sentido. Entendemos con ello el carácter trascendental de la difusividad de un sentido o de una sensación en el conjunto del sentir: la trascendentalidad del sentir tiene la medida de la globalidad de su difusividad carnal"]

10 Depraz, Natalie, Lucidité du corps, op. cit., p. 47. ["La resonancia es la promesa de una disponibilidad abierta al otro $[. .$.$] La resonancia pone de relieve, 1) vía la intersubjetividad comunitaria, la experiencia$ de la "chair" espiritual difusiva, y 2) vía la inter-afección pasiva, la experiencia del flujo carnal emocional. Tener una resonancia, encontrar un eco, expresiones que testimonian en nuestro lenguaje este acuerdo inter-afectivo, hecho de comprensión, de afinidad y de simpatía"] 
corps, op. cit., p. 62) ${ }^{11}$. Ya hemos indicado el papel preeminente que tiene la afección en contraste con la percepción. La apertura afectiva significa aquí auto-antecedencia. Y para afinar mejor aún esta dinámica de auto-antecedencia, N. Depraz hace comparecer la idea y el término de presentimiento, que aúna a) una cualidad de verdad subjetiva propia a la intuición, b) una cualidad temporal de pre-saber, marcado por el prefijo - pre, y c) la cualidad emocional a la que refiere la idea de sentimiento. Así, la auto-antecendencia significa que el cuerpo es presentimiento vivo, presentimiento encarnado de sí.

Nuestra conciencia carnal no nace como nacen las cosas sino que emerge de sí misma, se engendra ella misma. Ahora, esta emergencia define con precisión la condición trascendental de la temporalidad que somos. Natalie Depraz viene a desplazar el estatuto de absoluto dado a la forma pura del tiempo, para centrar la temporalidad en el cuerpo vivo y venir a afirmar que el absoluto fenomenológico es primeramente carnal (Depraz, N., Lucidité du corps, op. cit., p. 66). ¿Cómo hay que entender esta tesis? Una vez más, como resultado de un género de reducción trascendental no basado en la reflexión intelectual, sino en la reflexividad implicada en la auto-antecedencia que expresa la temporalidad propia del flujo carnal. No se pretende pues llegar a entrever algo de una vida supuestamente irreflexiva o prerreflexiva desde una instancia externa, sino poner de relieve la reflexividad sutil que emana del presentimiento, de la temporalidad carnal -y no formal- de la vida intencional. Para referir esta dimensión corporal abierta a su propio conocimiento, y sobre todo, a su propio ejercicio, Natalie Depraz utiliza el concepto lingüístico del futuro anterior, como metáfora para pensar este futuro ya encarnado en el presente protentivo de un cuerpo en movimiento.

Un nuevo paso se impone a continuación en la recomprensión de la corporalidad como lucidez. Un paso que revela el interés renovado por la relación entre el cuerpo y su imagen. La apuesta es la de resistir a la desubjetivación del cuerpo por la imagen. Para ello, Depraz conjuga un nuevo concepto modulador. Si en los contextos anteriores fueron con los conceptos de hiperestesia y de auto-antecedencia, esta vez es el concepto de trans-parution -que podríamos traducir como trans-parición-, empleado para significar la capacidad de la

\footnotetext{
${ }^{11}$ ["Nuestro cuerpo, el cuerpo que sentimos y que experimentamos, este cuerpo que es nuestra Urpraxis, encierra de modo primordial este poder de anticiparse él mismo a titulo de corporalidad que se inscribe en la espacio-temporalidad"]
} 
imaginación para atravesar la opacidad del cuerpo, sin por ello alcanzar una transparencia perfecta según la cual los sentimientos del otro se me darían desencarnados. De algún modo este concepto, en el régimen de la imaginación, corresponde a la idea de lucidez en la articulación global del texto, mediando una tercera vía entre la opacidad y la transparencia absolutas. Natalie Depraz, en diferentes modalidades discursivas y con diferentes ejemplos, busca esta superación de la mera apariencia corporal, sin desembocar por ello en una saturación absoluta de la donación corporal.

De fondo late la idea de que la imagen no viene a fijar las meras apariencias. Antes bien, la imagen se entiende como imagen móvil que resiste toda saturación. El ejemplo del rostro vivo, que no deja lugar a una objetivación definitiva, da buena cuenta de la imaginación que aquí se quiere recuperar, y con la que Natalie Depraz trata de resistir la pesadez a la que conducen ciertos usos políticos y publicitarios de la imagen. Contra estas imágenes estáticas e interesadas, N. Depraz moviliza la suspensividad de la imagen artística, caracterizada por un desinterés que contrasta con la imagen publicitaria, convertida en un medio para un fin. Contra el carácter reduccionista que caracteriza a la imagen pornográfica, que fragmenta los cuerpos convirtiéndolos en meros órganos desubjetivados, Natalie Depraz moviliza la imagen erótica, caracterizada por su ligereza. Todo ello para renovar el concepto y la idea misma de apariencia, tantas veces entendida en un sentido puramente negativo que oculta la fuerza que tiene este carácter fluido de la vida corporal. En el caso del rostro, el ejemplo ilustra el modo en que el otro, dado en su expresión siempre cambiante, moviliza continuamente mi imaginación, llamada a penetrar su mera aparición, impregnando sus propios sentimientos en los míos, dando con ello en la empatía una mayor corporalidad a su rostro y expresión. Se sobrepasa la mera aparición a partir de una imaginación empática, pero no para adivinar un estado espiritual desencarnado, sino para sentir el cuerpo del otro desde dentro; para incorporar, literalmente, sus emociones, sean éstas de dolor o de gracia.

Una vez más, entre un concepto negativo de apariencia y un concepto desencarnado de transparencia, la trans-parición implica una circulación dinámica entre la percepción y la imaginación, que impide que nos perdamos en los extremos de la opacidad del cuerpo inexpresivo y de la transparencia de un espíritu absolutamente desencarnado. Esta dinámica de una percepción que incluye la duda y la vacilación da lugar a un ensanchamiento del aparecer por medio de 
una mayor ligereza de la apariencia. En último término también el concepto de transparencia vendría renovado, incluyendo y envolviendo al cuerpo para designar precisamente la cualidad más sutil de la encarnación, aquella que pasa desapercibida al no llevar la atención sobre sí misma. Es allí donde la imaginación, en vez de permanecer en la opacidad de un cuerpo convertido en puro objeto de idolatría, en vez de atravesarlo hacia una dimensión desencarnada, lo interroga, adivinando las posibilidades que oculta la apariencia. Como lo dice la propia autora:

L'imagination n'est pas cette faculté fantoche d'irrealisation u-topique qui nous éloigne de la réalité rugueuse à étreindre, qui nous trans-porte dans le monde des songes sans consistance [...] L'imagination libère en nous le pouvoir d'envisager notre possibilité la plus intime, de nous confrontrer à des possibilités qui sont nôtres mais dont nous ne nous apercevons pas nécessairement. Elle porte à l'apparaître ces possibilités mêmes. L'imagination est cette capacité originaire de figuration qui seule donne un poids supérieur d'effectivité au réel -lequel n'est en fait que l'actualisation d'un seul possible- et ce, en potentialisant les autres possibles qui y sont co-inclus. ${ }^{12}$

\section{HACIA UNA ALTEROLOGÍA Y EMPIRISMO TRASCENDENTALES}

Lucidité du corps elabora un discurso que no trata sino de ser un aprendizaje, un ejercicio vuelto sobre el cuerpo. A partir de la circularidad implicada en los diferentes regimenes vistos hasta ahora -la hiperestesia, la autoantecedencia y la trans-parición- se busca reaprender y reavivar la dinámica de la lucidez que, por sernos tan íntima, nos pasa desapercibida. La heterogeneidad descrita, a través de diferentes ejemplos que se encadenan uno al otro - Natalie Depraz pone ejemplos vividos en primera persona que sin embargo pueden ser compartidos en alto grado, al hablar de la danza, del erotismo o del embarazo- da pie a una revitalización de la fluidez del cuerpo, siempre en los

\footnotetext{
12 Depraz, Natalie. Lucidité du corps, op. cit., p. 137 ["La imaginación no es aquella facultad fantoche de irrealización u-tópica que nos aleja de la ruda realidad que nos atenaza, que nos trans-porta a un mundo de sueños sin consistencia [...] La imaginación libera en nosotros el poder que da acceso a nuestra posibilidad más íntima, que nos confronta a aquellas posibilidades que siendo nuestras no necesariamente apercibimos como tales. Ella lleva al orden del aparecer estas mismas posibilidades. La imaginación es aquella capacidad originaria de figuración que por sí misma da un peso superior de efectividad a lo real - que no es de hecho más que la actualización de una de las posibilidades- al potenciar aquellas otras posibilidades que están co-incluidas"]
} 
límites de su fragilidad. Todo ello nos lleva poco a poco a tratar de encarnar la cuestión trascendental de la fenomenología, elaborando un empirismo que no se oponga al idealismo, y tratando de comprender la alteridad inmanente que nos habita a partir de la alteridad del otro según cuatro modelos de subjetividad, a saber, la animal, la infantil, la alienada y la extranjera.

Estos son temas que desbordan el libro Lucidité du corps y atraviesan la filosofía de N. Depraz de principio a fin. Por un lado se busca dar a la alteridad un estatuto que no solo venga dado desde fuera, como un añadido a la subjetividad. Se quiere ver una alteridad a sí primera, que viene a funcionar como un a priori de la vida subjetiva, dando a la idea de intersubjetividad un doble valor conjugado. 1) Inter-subjetividad como relación entre dos o más sujetos, revelando la posibilidad de la amistad, del erotismo, del amor, de la comunidad. Pero 2) inter-subjetividad, también, como relación interna, como alteridad inmanente y anterior a la escisión que produce la reflexión sobre la vida ${ }^{13}$.

Todos los órdenes de circularidad que articulan la lucidez de la encarnación, entre opacidad y transparencia, se envuelven ahora en la circularidad que va de la alteridad inmanente a la alteridad del otro en un complejo de idas y vueltas que realimenta la comunidad generativa. En esta circularidad generativa y regenerativa el cuerpo no es un mero instrumento, sino un verdadero órgano de alteridad y alteración, de sí y del otro en una misma comunidad de sujetos.

A continuación se incorpora un nuevo valor a la circularidad de la "chair" trascendental, esta vez mediante los polos del empirismo y del idealismo ${ }^{14}$. Partiendo de la fenomenología genética, especialmente en relación a la constitu-

\footnotetext{
${ }^{13}$ La alteridad interna o alteridad primera a sí -alterité a soi- ha sido tratada por Natalie Depraz en su libro Transcendance et incarnation. Le statut de l'intersubjectivité comme altérité à soi chez Husserl. Paris, Librairie Philosophique J. Vrin, 1995.

14 "La trascendantalité correspond au niveau génétique de l'auto-constitution du flux de la conscience. On ne thématise pas seulement l'objet en tant qu'il apparaît à la conscience, mais d'abord la genèse subjective de sa constitution. La conscience se prend par conséquent elle-même pour thème en tant que mouvement vécu émergent, en tant que processus d'avènement : elle y devient "la chose elle-même". Or une telle genèse structurée des vécus de la conscience, loin de se definir comme une simple condition formelle de possibilité, est elle-même incarnée, innervée d'une dynamique concrète et materielle. La mobilité intime de nos sensations et l'intensité de nos affects sont des vécus matériels homologues dans leur teneur au contenu hylétique et kinesthésique de l'objet que en supporte l'apparaître" (Depraz, Natalie, Lucidité du corps, op. cit., p. 216) ["La trascendentalidad corresponde al nivel genético de la autoconstitución del flujo de la conciencia. No se tematiza solamente el objeto en tanto que aparece a la conciencia, sino antes de nada la génesis subjetiva de su constitución. La conciencia se toma en consecuencia ella misma por tema en tanto que movimiento vivido emergente, en tanto que proceso de advenimiento: ella se vuelve "la cosa misma". Ahora bien, una tal génesis estructurada de las vivencias de la conciencia, lejos de definirse como una simple condición formal de posibilidad, está ella misma encarnada, inervada por una dinámica concreta y material. La movilidad íntima de nuestras sensaciones y la intensidad de nuestros afectos son vivencias materiales homólogas, en lo que respecta a su tenor, al contenido hylético y kinestésico del objeto que soporta el aparecer"]
} 
ción de la intersubjetividad, N. Depraz estudia la pertinencia de incluir la corporalidad del otro en la constitución de su carácter de alter ego, y en consecuencia, de asumir la propia corporalidad como una suerte de a priori de la constitución de la intersubjetividad, en el doble sentido expuesto: el otro como alter ego, y yo mismo como alter ego; intersubjetividad según la doble valencia del prefijo -inter.

Hay que añadir, en último lugar, dos nuevos elementos que realimentan la lucidez del cuerpo mediante su circularidad: son la actitud trascendental y la actitud natural, que vienen a completar la dinámica que venimos subrayando, compuesta por los dos regímenes de alteridad -interna y externa- y por la conjugación del empirismo y el idealismo. N. Depraz trata de aproximar las dos actitudes - natural y trascendental- al repensar el significado de la corporalidad en la constitución del mundo entendido como mundo de la vida. Sin llegar a confundir estos dos órdenes, N. Depraz cree necesaria la reducción a la "chair" trascendental, como complemento imprescindible de las reducciones cartesiana y psicológica. Esta nueva reducción, por vía de la encarnación, plantea precisamente una experiencia de la fluidez y de la lucidez del cuerpo, después de haber puesto entre paréntesis la densidad y pesadez de un cuerpo puramente físico. Lo que se pone de manifiesto son las cosas tal y como me son dadas en calidad de sujeto encarnado. Con ello, subrayando la estructuración que parte de los modos de darse los objetos y el mundo mismo, se destaca también la dinámica experiencial en la cual la cosa y la conciencia se engendran mutuamente sin ser por ello reconducidas a una misma realidad homogénea ${ }^{15}$. Entre un ejercicio físico excesivamente mercantilizado y explotado por la cultura publicitaria del cuerpo en forma, entre un conocimiento anatómico hipocondríaco alimentado por el miedo a envejecer, y entre una cultura del desnudo excesivamente objetivadora y cosificante, la reducción a la "chair" trascendental nos conduce a una erótica de los cuerpos, a un conocimiento y una conciencia sutiles de la carnalidad, y a un tipo de actividad que envuelva la buena forma física en una mejor forma metafísica, a partir de experiencias espirituales que sobrepasen la instrumentalización del cuerpo.

En conclusión, hay que afirmar que no es posible elaborar una fenomenología de la subjetividad que no pase por la aprehensión que tenemos de noso-

${ }^{15}$ Véase Depraz, Natalie, Plus sur Husserl, op. cit., pp. 18-19. 
tros mismos. Y habrá que reconocer que toda aprehensión y apercepción de sí pasa por el a priori carnal que está en juego en las actividades de autoconstitución de la conciencia y de constitución de los otros. Como lo dirá varias veces N. Depraz, aunque el cuerpo no constituye propiamente nada, aunque no es constituyente, es irremediablemente constitutivo de la subjetividad.

Puisque notre expérience du monde et des autres repose tout d'abord sur la finesse et la qualité tangibles de notre chair, c'est-à-dire sur notre capacité à nous appréhender nous-mêmes comme des êtres sensibles c'est-à-dire lucides, tout à la fois corporels, psychiques et spirituels, le corps revêt le statut d'un a priori de notre expérience, lui-même expérimentable puisqu'il est I'objet par nous-mêmes d'une auto-expérience. ${ }^{16}$

\footnotetext{
${ }^{16}$ Depraz, Natalie, Lucidité du corps, op. cit., p. 205. ["Porque nuestra experiencia del mundo y de los otros reposa antes de nada sobre la fineza y la cualidad tangible de nuestra "chair", es decir sobre nuestra capacidad para aprehendernos a nosotros mismos como seres sensibles y lucidos, a la vez corporales, psíquicos y espirituales, el cuerpo releva su estatuto de a priori de nuestra experiencia, él mismo experimentable en tanto es el objeto para nosotros mismos de una auto-experiencia"]
} 